\title{
Polymers of 4-Thieno[3,2-b]thiophen-3-ylbenzonitrile with Anthracene and Biphenyl: Their electronic and optoelectronic properties
}

\author{
Recep Isci 1, Ahsen Sare Yalin 1, Dilara Gunturkun 1, Turan Ozturk 1,2, * \\ 1 Istanbul Technical University Department of Chemistry, Faculty of Science, Maslak, Istanbul 34469, Turkey \\ 2 TUBITAK UME, Chemistry Group Laboratories, PBox 54, 41470, Gebze-Kocaeli, Turkey \\ * Correspondence: ozturktur@itu.edu.tr \\ + Presented at the 23nd International Electronic Conference on Synthetic Organic Chemistry, 15 November- \\ 15 December 2019.
}

\begin{abstract}
Design and synthesis of conjugated organic polymers for electronic and optoelectronic applications, such as electrochromic devices (ECD), organic light emitting diodes (OLED), organic field effective transistors (OFET), lasers, photodiodes and solar cells, have an increasing momentum. Fused thiophenes, i.e. thieno[3,2-b]thiophenes (TT), have been widely accepted as important building blocks for such materials. In this work, 4-thieno[3,2-b]thiophen-3-ylbenzonitrile (TT-CN), having electron withdrawing cyano moiety, was polymerized with anthracene and biphenyl through Suzuki coupling to obtain the polymers. Electronic and optical properties of the resultant polymers were investigated. Effects of different molecular orientations of anthracene and biphenyl blocks in the polymer backbone were compared.
\end{abstract}

\section{Introduction}

Design and synthesis of conjugated organic polymers for electronic and optoelectronic applications, such as electrochromic devices (ECD), organic light emitting diodes (OLED), organic field effective transistors (OFET), lasers, photodiodes and solar cells, have an increasing momentum1-3. Conjugated organic semiconductors have been a subject of considerable interest, not only for the exploration of their fundamental structure-property relationships, specifically, for their electrical or optical properties. Fused thiophenes, i.e. thieno[3,2-b] thiophenes (TT), have been widely accepted as important building blocks for such polymeric materials4-7. Thienothiophenes, in general, have four isomers formed through the orientations of the sufur atoms of the thiophene rings, among which thieno[3,2-b]thiophene belongs to the most widely used TTs as it provides continuous conjugation through two fused thiophenes and polymer backbone. Moreover, presence of two sulfur atoms makes them electron-rich, enabling to be used as electron donating moieties in construction of polymeric materials [1-7]

Compared with polymers, small molecule semiconductors own the advantages of high purity and ordered packing, which are key factors for electronic and optic properties. Among the small molecules, anthracene and biphenyl, with low $\mathrm{C}-\mathrm{H}$ ratio and a highly conjugated planar structure have attracted the most attention for organic polymeric materials. Anthracene, consisting of three rigid fused benzene rings, the least conjugated but the most soluble and most stable member of the acenes, has been given great consideration for organic polymeric materials. In addition, the anthracene part is compatible with the $\pi$-electron-rich structure for good electron transport. Furthermore, chemical modifications of anthracene would tune the molecular packing and charge transport properties, and fortunately, aryl groups, used to extend the p-system, like phenyl, thiophene, and thienyl, could be very easily attached to anthracene at the active end- and peripositions by couplings in high yield. Another conjugated and ordered packing aromatic molecule is biphenyl. Biphenyl, by torsion angle $\Phi$ between the planes of the two phenyl rings that the degree of 
$\pi$-overlap in the two phenyl rings and the resulting extent of $\pi$-systems delocalization can be finetuned. In addition, biphenyls play important roles as $\pi$-conjugated bridge and as electron rich donor like anthracene [8,9]. These roles give them the ability to become UV and electro applicable properties. In this work, 4-thieno[3,2-b]thiophen-3-ylbenzonitrile (TT-CN), having electron withdrawing cyano moiety, was polymerized with anthracene and biphenyl through Suzuki coupling to obtain the polymers $\mathbf{1}$ and 2, respectively8,9. Reason for using CN group on TT is to obtain polymeric material suitable for donor-acceptor (D-A) model. Besides, cyano groups into the polymer backbone usually lowers its LUMO level, leading to an increased electron affinity anddecreased band gap energy. Electronic and optical properties of the resultant polymers were investigated. Effects of different molecular orientations of anthracene and biphenyl blocks in the polymer backbone were compared.

\section{Materials and Methods}

\subsection{Materials}

3-Bromothiophene (97\%, Across), 2-bromo-4-cyanoacetophenone (96\%, Sigma-Aldrich), polyphosphoric acid (PPA, 115\% H3PO4 basis, Sigma-Aldrich), n-butyllityum (2.5 M in hexanes, Sigma-Aldrich), 4-bromotriphenylamine (97\%, Sigma-Aldrich), sodium sulfate (Merck), tetrakis(triphenylphosphine)palladium $(0)$ ( $\mathrm{Pd}(\mathrm{PPh} 3) 4$, 99\%, Sigma-Aldrich), 2-isopropoxy-4,4,5,5tetramethyl-1,3,2-dioxaborolane (98\%, Aldrich),, diphenylmethane (99\%, Sigma-Aldrich), and 4bromobenzophenone (98\%, Sigma-Aldrich) were used as received. Diethyl ether and THF were dried over metallic sodium. Dimethylformamide (EMPARTA, HPLC grade) was stored over activated molecular sieves (4 Å).Dichloromethane (Aldrich), toluene (Merck), and sodium bicarbonate (Merck) were used as received.

\subsection{Synthesis of 4-[2-(Thiophen-3-ylsulfanyl)acetyl]benzonitrile (TAB)}

To a solution of 3-bromothiophene $(3 \mathrm{~g}, 18.40 \mathrm{mmol})$ in dry diethyl ether was added $\mathrm{n}$ butyllithium $(8.1 \mathrm{~mL}, 27 \mathrm{mmol})$ dropwise at $-78{ }^{\circ} \mathrm{C}$, under nitrogen atmosphere. After the reaction was stirred for $1 \mathrm{~h}$, elemental sulfur (S8) $(0.65 \mathrm{~g}, 20.24 \mathrm{mmol})$ was added, and the mixture was further stirred for an additional $1 \mathrm{~h}$. Then, the temperature was brought to $0{ }^{\circ} \mathrm{C}$ and $4-(2-$ bromoacetyl)benzonitrile $(4.53 \mathrm{~g}, 20.24 \mathrm{mmol})$ was introduced portion wise into the mixture. Stirring was continued overnight, and the reaction was quenched with water. The solution was extracted with dichloromethane 3 times, and the organic layer was washed with NaHCO3 $(10 \%)$ and water. The organic layer was dried over $\mathrm{Na} 2 \mathrm{SO} 4$, filtered and the solvent was evaporated under reduced pressure. The crude product was purified by flash column chromatography eluting with nhexane: $\mathrm{CH} 2 \mathrm{Cl} 2$ (3:1) to give the title compound as a white powder $(4.02 \mathrm{~g}, 84 \%)$. $1 \mathrm{H} \mathrm{NMR}(\mathrm{CDCl} 3$, $500 \mathrm{MHz}): \delta=8.00-7.99(\mathrm{~d}, 2 \mathrm{H}), 7.78-7.76(\mathrm{~d}, 2 \mathrm{H}), 7.33(\mathrm{dd}, \mathrm{J}=5.0,3.0 \mathrm{~Hz}, 1 \mathrm{H}), 7.26(\mathrm{dd}, \mathrm{J}=3.1,1.3$ $\mathrm{Hz}, 1 \mathrm{H}), 7.02(\mathrm{dd}, \mathrm{J}=5.0,1.3 \mathrm{~Hz}, 1 \mathrm{H}), 4.12(\mathrm{~s}, 2 \mathrm{H}) .13 \mathrm{C} \mathrm{NMR}(\mathrm{CDCl} 3,126 \mathrm{MHz}): \delta=192.73,138.35$, $132.56,130.37,129.07,128.66,127.57,126.80,117.83,116.59,41.92$.

\subsection{Synthesis of 4-Thieno[3,2-b]thiophen-3-ylbenzonitrile (TT)}

To a solution of polyphosphoric acid (PPA) $(2.5 \mathrm{~g}, 23 \mathrm{mmol})$ in chlorobenzene $(5 \mathrm{~mL})$ at $135{ }^{\circ} \mathrm{C}$ was added TAB $(0.6 \mathrm{~g}, 2.3 \mathrm{mmol})$ dissolved in chlorobenzene $(10 \mathrm{~mL})$ drop wisely. The reaction was heated at this temperature for 6-7 h, after which the mixture was extracted with $\mathrm{CH} 2 \mathrm{Cl} 2$, sodium bicarbonate (30\% solution) and with water. The organic layer was dried over $\mathrm{Na} 2 \mathrm{SO} 4$, filtered and the solvent was evaporated under reduced pressure. The residue was purified by column chromatography eluting with n-hexane: $\mathrm{CH} 2 \mathrm{Cl} 2(4: 1)$ to obtain the title compound TTB $(0.39 \mathrm{~g}, 69 \%)$. 1H NMR (CDCl3, $500 \mathrm{MHz}): \delta=7.85(\mathrm{~d}, \mathrm{~J}=8.8 \mathrm{~Hz}, 2 \mathrm{H}), 7.74(\mathrm{~d}, \mathrm{~J}=8.2 \mathrm{~Hz}, 2 \mathrm{H}), 7.64(\mathrm{~s}, 1 \mathrm{H}), 7.45$ (d, J $=5.3 \mathrm{~Hz}, 1 \mathrm{H}), 7.34(\mathrm{~d}, \mathrm{~J}=5.3 \mathrm{~Hz}, 1 \mathrm{H})$; 13C NMR $(\mathrm{CDCl} 3,126 \mathrm{MHz}): \delta=140.14,138.76,137.30,132.80$, $132.68,127.71,126.52,125.05,119.94,118.80,110.91$. 


\subsection{Synthesis of 4-(2,5-Dibromothieno[3,2-b]thiophen-3-yl)benzonitrile (Br-TT-Br)}

To a solution of TT ( $200 \mathrm{mg}, 0.83 \mathrm{mmol})$ dissolved in DMF $(6 \mathrm{~mL})$ was added NBS ( $295 \mathrm{mg}, 0.166$ $\mathrm{mmol})$ at $-10^{\circ} \mathrm{C}$ in the dark. After the reaction was stirred for $8 \mathrm{~h}$ at the same temperature, the mixture was poured into water $(50 \mathrm{~mL})$ and the precipitate filtrated and purified by column chromatography eluting with hexane:CH2Cl2 (3:1) to obtain Br-TT-Br (0.26 g, 78\%). $1 \mathrm{H} \mathrm{NMR} \mathrm{(CDCl3,} 500 \mathrm{MHz}): \delta=$ 7.81-7.75 (m, 4H), $7.24(\mathrm{~s}, 1 \mathrm{H})$; 13C NMR (CDCl3,126 MHz): $\delta=138.34,137.88,136.65,132.70,131.66$, 129.10, 122.32, 118.45, 114.21, 112.37, 111.53 .

\subsection{Synthesis of 9,10-dibromoanthracene}

To a solution of anthracene $(10 \mathrm{~g}, 56 \mathrm{mmol})$ dissolved in $\mathrm{CHCl}_{3}(150 \mathrm{ml})$ and was added elemental bromine ( $5.8 \mathrm{ml}, 2.01 \mathrm{eq}$ ) by using pipette. The reaction was heated at room temperature for $5 \mathrm{~h}$. After that, the mixture was waited for boiling of $\mathrm{CHCl}_{3}$. The mixture was heated in a beaker. Then, it was cooled in ice bath for crystallization. The precipitated solid particles were filtered and allowed to dry in vacuum oven. $15.2 \mathrm{~g}$ yellow product was obtained with yield of $81 \% .{ }^{1} \mathrm{H} \mathrm{NMR}\left(500 \mathrm{MHz}, \mathrm{CDCl}_{3}\right)$ $\delta 8.63-8.56(\mathrm{~m}, 4 \mathrm{H}), 7.70-7.60(\mathrm{~m}, 4 \mathrm{H})$.

\subsection{Synthesis of 9,10-bis(4,4,5,5,-tetramethyl-1,3,2-dioxaborolan-2-yl)anthracene}

To a solution of 9,10-dibromoanthracene $(2 \mathrm{~g}, 5.95 \mathrm{mmol})$ and bis(pinacolato)diboron ( $3.7 \mathrm{~g}$, $14 \mathrm{mmol})$ dissolved in DMF (45 ml). After the reactants completely dissolved, potassium acetate (1.8 $\mathrm{g}, 3 \mathrm{eq}$ ) was added onto the mixture. The mixture was treated with the gas of $\mathrm{N}_{2}$ for a while and $\mathrm{Pd}$ (II) was added as a catalyzer. It was allowed to mix at $80^{\circ} \mathrm{C}$ for all night. The mixture was filtered from celitte for holding the Pd (II). After the boiling of DMF, the mixture was extracted with $\mathrm{CH}_{2} \mathrm{Cl}_{2}$, sodium carbonate, and water. The organic layer was dried with $\mathrm{Na}_{2} \mathrm{SO}_{4}$, filtered and thr solvent was evaporated under reduced pressure. The mixture was purified by column chromatography eluting with $\mathrm{CH}_{2} \mathrm{Cl}_{2}$ : hexane ( 8:1). 1.53 g yellowish-white product was obtained with yield of $60 \% . \quad{ }^{1} \mathrm{H} \mathrm{NMR}$ $\left(500 \mathrm{MHz}, \mathrm{CDCl}_{3}\right) \delta 8.38-8.31(\mathrm{~m}, 4 \mathrm{H}), 7.50-7.41(\mathrm{~m}, 4 \mathrm{H}), 1.58(\mathrm{~s}, 24 \mathrm{H})$.

\subsection{Synthesis of the Copolymer of Anthracene-TT-CN}

To a solution of 4-(2,5-dibromothieno[3,2-b] thiophen-3-yl) benzonitrile (100 mg, $0.25 \mathrm{mmol})$ and 9,10-bis(4,4,5,5-tetramethyl-1,3,2-dioxaborolan-2-yl) anthracene ( $110 \mathrm{mg}, 0.25 \mathrm{mmol}$ ) were dissolved with toluene $(30 \mathrm{ml}) \cdot \mathrm{K}_{2} \mathrm{CO}_{3}(3 \mathrm{~g})$ was dissolved with water $(10 \mathrm{ml})$. The solution of $\mathrm{K}_{2} \mathrm{CO}_{3}$ was added onto the mixture after all reactants were dissolved. The mixture was treated with the gas of $\mathrm{N}_{2}$ for 5 min. $\operatorname{Pd}(0)$ was added as catalyzer and the mixture was allowed to mix at $115^{\circ} \mathrm{C}$ for 2 days. The mixture was filtered from celitte for holding $\operatorname{Pd}(0)$. After boiling of toluene, the mixture was precipitated with cool methanol and was allowed to dry in vacuum oven. The polymer of 4-(5methyl-2-(10-methylanthracen-9-yl)thieno[3,2-b]thiophen-3-yl)benzonitrile was obtained.

\subsection{Synthesis of the 4,4'-bis(4,4,5,5-tetramethyl-1,3,2-dioxaborolan-2-yl)-1,1'-biphenyl}

To a solution of 4,4'-dibromo-1,1'-biphenyl ( $2 \mathrm{~g}, 6.41 \mathrm{mmol}$ ) and bis(pinacolato)diboron ( $3.91 \mathrm{~g}$, $15.4 \mathrm{mmol})$ dissolved in DMF $(45 \mathrm{ml})$. When all reactants completely dissolved, $\mathrm{K}_{2} \mathrm{CO}_{3}(1.8 \mathrm{~g}, 3 \mathrm{eq})$ was added into the mixture. The mixture was treated with the gas of $\mathrm{N}_{2}$ for a while and $\mathrm{Pd}(\mathrm{II})$ was 
added as a catalyzer. It was allowed to mix at $80^{\circ} \mathrm{C}$ for all night. The mixture was filtered from celitte for holding the $\mathrm{Pd}(\mathrm{II})$. After the boiling of $\mathrm{DMF}$, the mixture was extracted with $\mathrm{CH}_{2} \mathrm{Cl}_{2}$, sodium carbonate, and water. The organic layer was dried with $\mathrm{Na}_{2} \mathrm{SO}_{4}$, filtered and thr solvent was evaporated under reduced pressure. The mixture was purified by column chromatography eluting with $\mathrm{CH}_{2} \mathrm{Cl}_{2}$ :hexane ( 8:1). $1.85 \mathrm{~g}$, white product was obtained with yield of $71 \%$.

\subsection{Synthesis of the Polymer of the TT-CN-Biphenyl}

To a solution of 4-(2,5-dibromothieno[3,2-b]thiophen-3-yl)benzonitrile ( $100 \mathrm{mg}, 0.25 \mathrm{mmol}$ ) and 4,4'-bis(4,4,5,5-tetramethyl-1,3,2-dioxaborolan-2-yl)-1,1'-biphenyl ( $100 \mathrm{mg}, 0.24 \mathrm{mmol}$ ) were dissolved with toluene $(30 \mathrm{ml}) . \mathrm{K}_{2} \mathrm{CO}_{3}(3.14 \mathrm{~g})$ was dissolved with water $(10 \mathrm{ml})$. The prepared solution of $\mathrm{K}_{2} \mathrm{CO}_{3}$ was added onto the mixture. The mixture was treated with the gas of $\mathrm{N}_{2}$ for 5 min. $\operatorname{Pd}(0)$ was added as catalyzer and the mixture was allowed to mix at $100^{\circ} \mathrm{C}$ for 2 days. The mixture was filtered from celitte for holding $\operatorname{Pd}(0)$. After boiling of toluene, the mixture was precipitated with cool methanol and was allowed to dry in vacuum oven. The polymer was obtained.

\section{Results and Discussion}

\subsection{Synthesis}

4-thieno[3,2-b]thiophen-3-ylbenzonitrile (TT-CN was polymerized with biphenyl and anthracene through Suzuki coupling to obtain the polymers P1 and P2, respectively (Scheme 1).
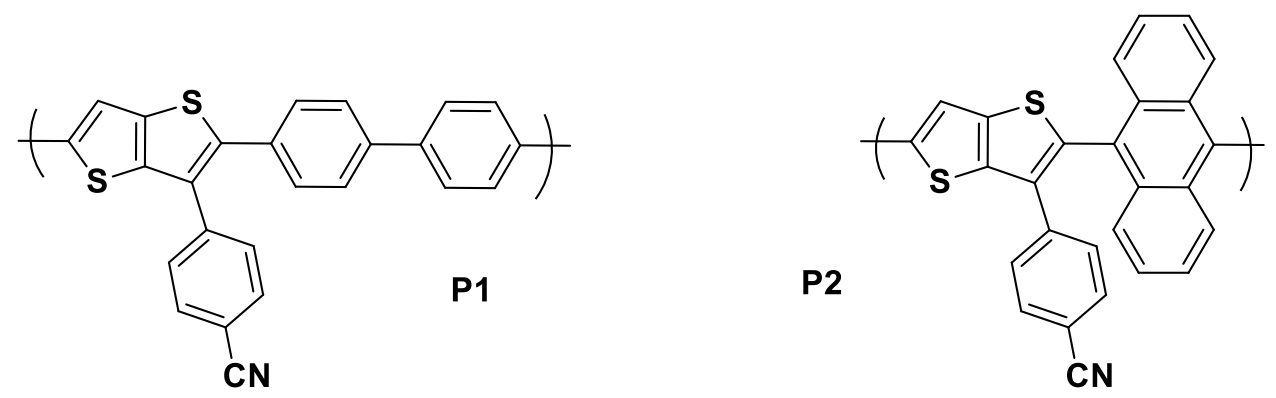

Scheme 1. Polymer of TT-Biphenyl (P1) and Polymer of TT-Anthracene (P2)

Synthesis of the intermediate, 4-[2-(thiophen-3-ylsulfanyl)acetyl]benzonitrile was conducted by lithiation of 3-bromothiophene with n-butyllithium at $-78{ }^{\circ} \mathrm{C}$, which was followed by addition of elemental sulfur and then 4-(2-bromoacetyl)benzonitrile. Ring closure reaction of in the presence polyphosphoric acid (PPA) in refluxing chlorobenzene gave 4-thieno[3,2-b]thiophen-3-ylbenzonitrile (TT). Bromination of TT, using NBS at $-10^{\circ} \mathrm{C}$ in DMF, produced Br-TT-Br (Scheme 2).

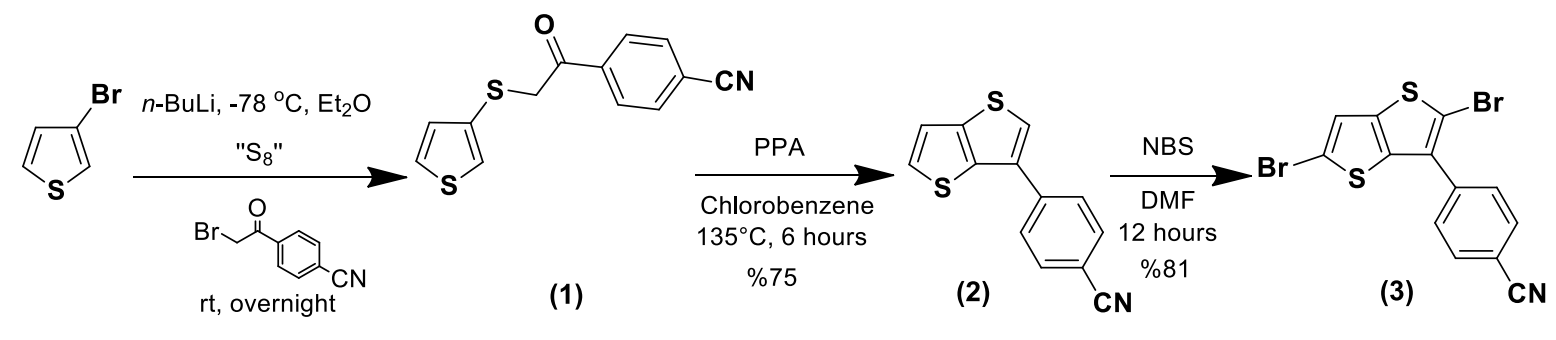


Scheme 2. Synthesis of Dibromo Derivative of Thienothiophen

Dibromination of anthracene yielded dibromoanthracene 4. In order to make it ready for a Suzuki polymerization in the next step, it was borolated to obtain 5 (Scheme 3).<smiles>c1ccc2cc3ccccc3cc2c1</smiles><smiles>CC(C)(Br)C(C)(Br)Br</smiles>
rt, 5 hours $\% 81$<smiles>Brc1c2ccccc2c(Br)c2ccccc12</smiles>

(4)

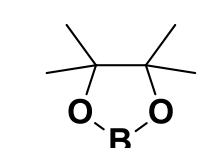

' $\mathbf{B}^{\prime}$

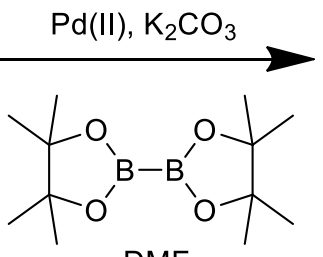

DMF

$80^{\circ} \mathrm{C}$, overnight

$\% 60$<smiles>[B]c1c2ccccc2c(B2OC(C)(C)C(C)(C)O2)c2ccccc12</smiles>

(5)

Scheme 3. Synthesis of 9,10-bis(4,4,5,5,-tetramethyl-1,3,2-dioxaborolan-2-yl)anthracene

To obtain other polymer, dibromobiphenyl was borolayted to obtain 6 for Suzuki polymerization (Scheme 4).<smiles>C#Cc1ccc(-c2ccc(C)cc2)cc1</smiles>

\section{$\mathbf{E}$}<smiles></smiles>

पDFF

ESOaenigt

वा

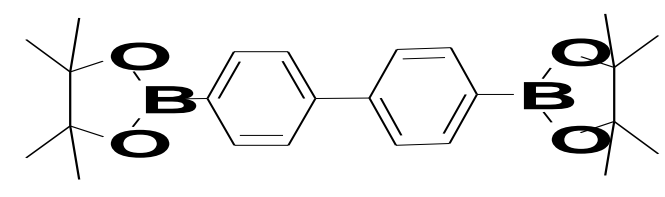

(9)

Scheme 4. Synthesis of the 4,4'-bis(4,4,5,5-tetramethyl-1,3,2-dioxaborolan-2-yl)-1,1'-biphenyl

The Br-TT-Br (3) was polymerized via Suzuki coupling with 9,10-bis(4,4,5,5,-tetramethyl-1,3,2dioxaborolan-2-yl)anthracene (5) and the 4,4'-bis(4,4,5,5-tetramethyl-1,3,2-dioxaborolan-2-yl)-1,1'biphenyl (6) to obtain the polymers P1 and P2 (Scheme 5). 


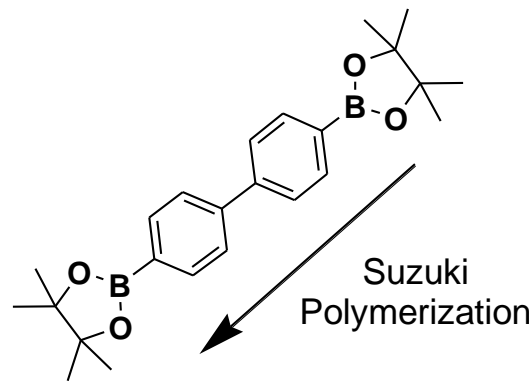<smiles>Cc1cc2sc(-c3ccc(-c4ccc(C(C)(C)C)cc4)cc3)c(-c3ccc(C(C)(C)C)cc3)c2s1</smiles><smiles>N#Cc1ccc(-c2c(Br)sc3cc(Br)sc23)cc1</smiles>

Suzuki<smiles></smiles>
Polymerization<smiles></smiles>

Scheme 5. Synthesis of TT-Biphenyl (P1) and Polymer of TT-Anthracene (P2)

\subsection{Optical Properties}

The spectroscopic characterization of the two compounds was carried out in tetrahydrofuran solutions. While the p(TT-Biphenyl) P1 showed intense UV-visible absorption bands in the $380 \mathrm{~nm}$ region, the p(TT- Ant) P2 showed absorption maxima at the 260 and $400 \mathrm{~nm}$ (Figure 1, Table1).
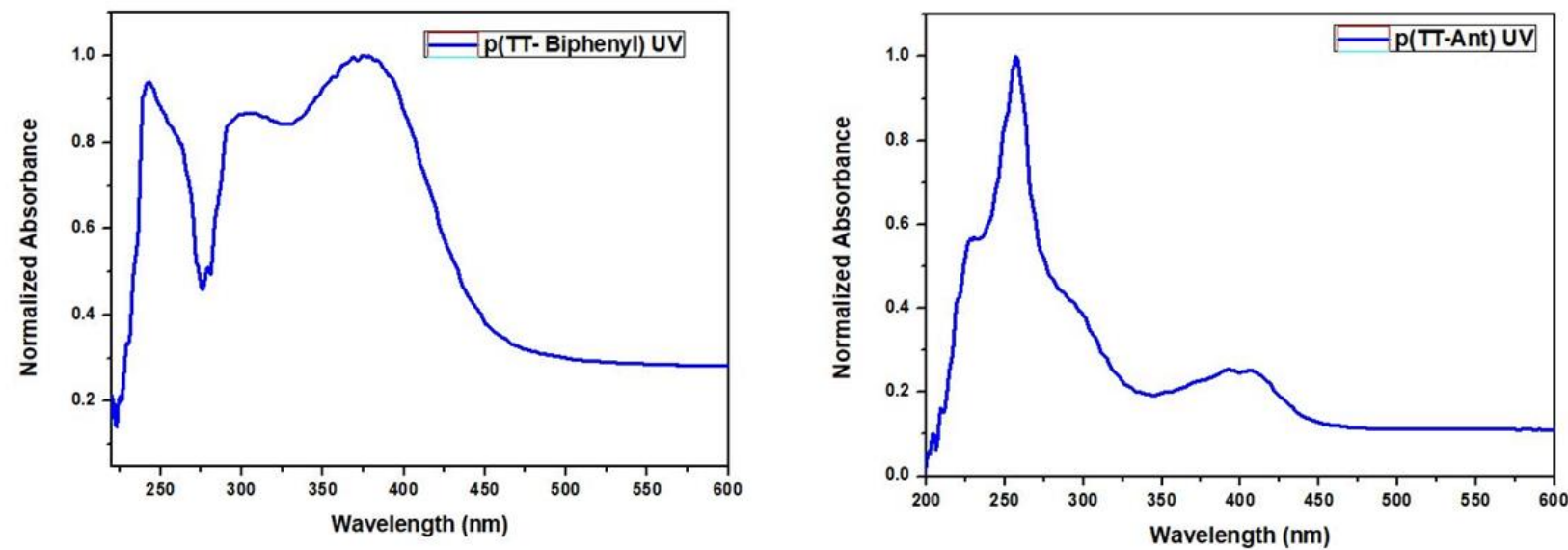

Figure 1. UV-Vis Spectra of P1 and P2

Through the study of the fluorescence of polymers P1 and P2. It was possible to observe bands with maximum wavelengths at $480 \mathrm{~nm}$ and $515 \mathrm{~nm}$, respectively (Figure 2, Table 1). 

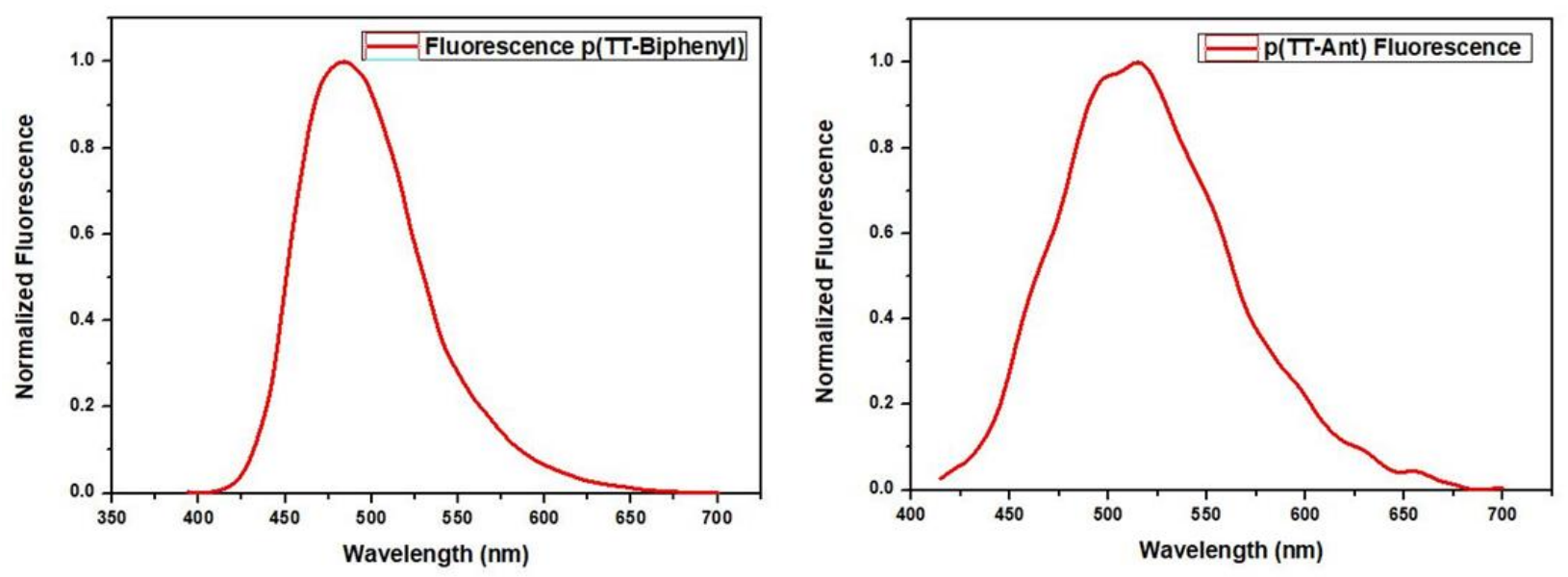

Figure 2. Fluorescence Spectra of P1 and P2

Table 1. UV-visible and Fluorescence Absorption Data for P1 and P2

\begin{tabular}{cccc}
\hline Polymers & $\lambda_{\max }-\mathrm{UV}(\mathrm{nm})$ & $\lambda_{\max }$ - Fluorescence (nm) & Eopt $^{(\mathrm{eV})}$ \\
\hline p(TT-Biphenyl) P1 & 380 & 480 & \\
& & & 2.64 \\
$\mathbf{p}$ (TT- Ant) P2 & 260,400 & 515 & 2.61 \\
\hline
\end{tabular}

\subsection{Electrochemical Properties}

Electrochemistry of the polymers $\mathbf{P 1}$ and $\mathbf{P} \mathbf{2}$ were conducted in a cyclic voltammetry (CV), using $\mathrm{Pt}$ wires as working and counter electrodes and $\mathrm{Ag}$ wire as a reference electrode. On the anodic scans, polymer reductions were observed at about $-0.75 \mathrm{~V}$ for P1, $-0.64 \mathrm{~V}$ and for P2 .Oxidation of the polymers formed a peak at $+1.28 \mathrm{~V}$ for $\mathrm{P} 1$ and $+1.42 \mathrm{~V}$ for $\mathrm{P} 2$. 

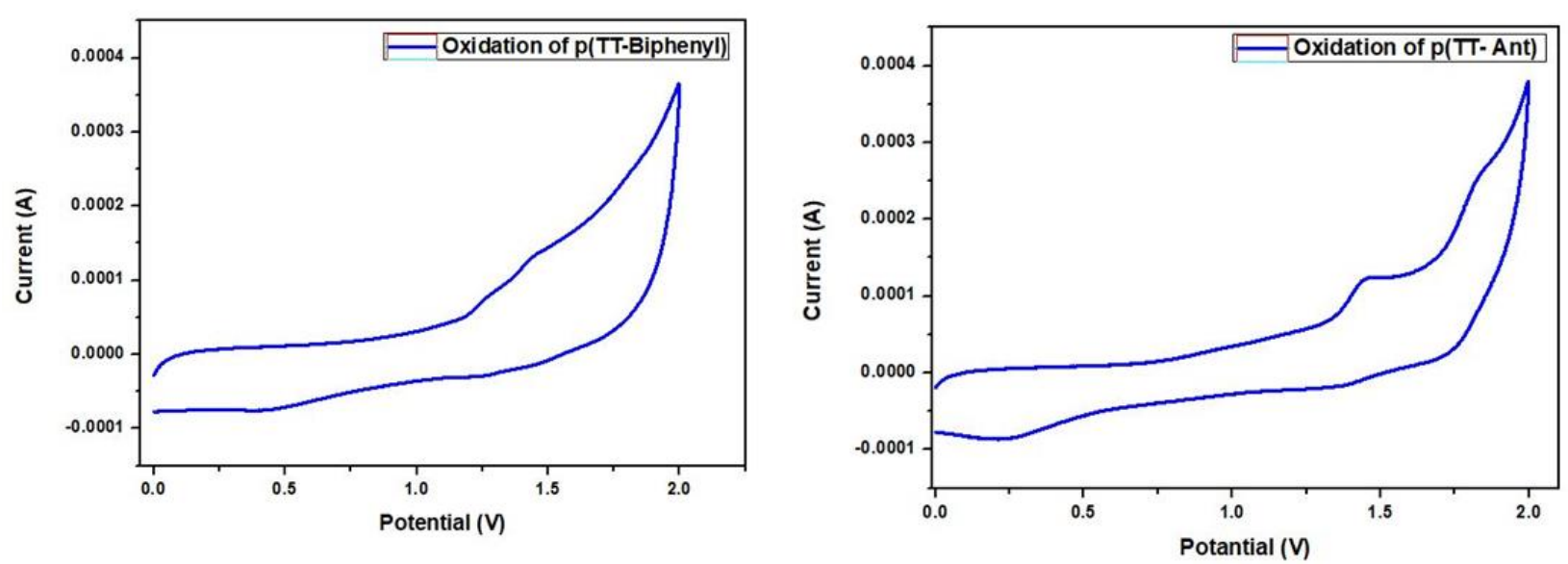

Figure 3. Cyclic Voltammograms of P1 and P2 for Oxidation
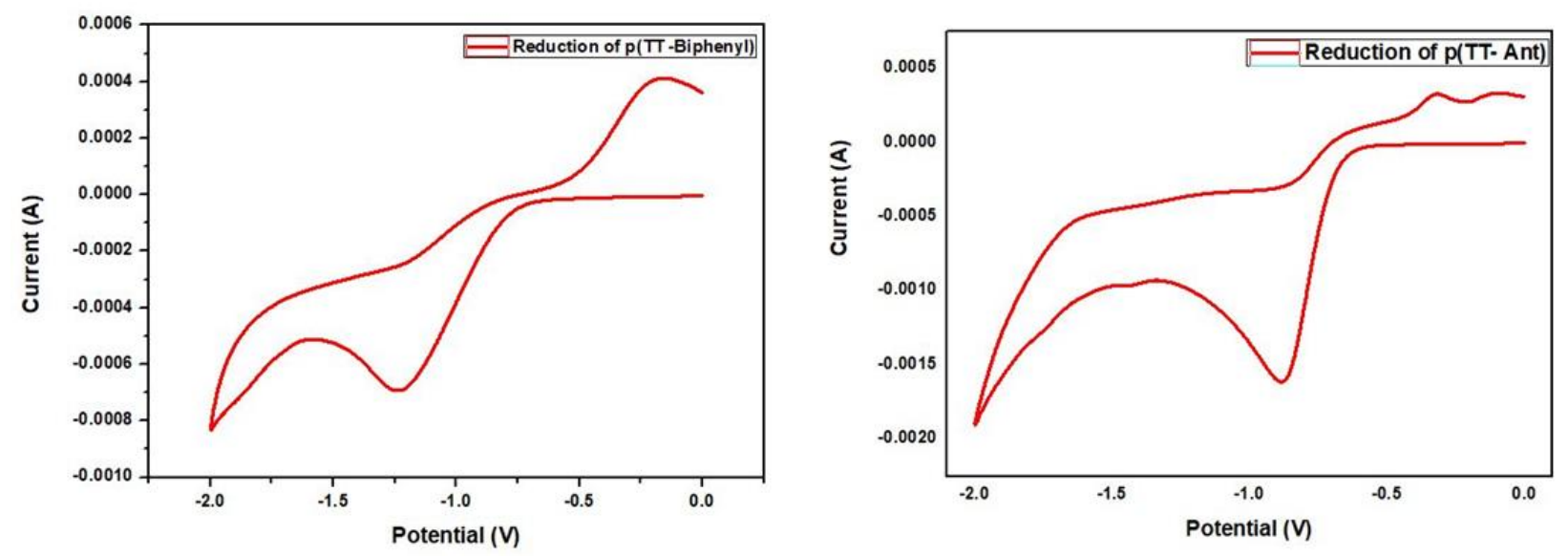

Figure 4. Cyclic Voltammograms of P1 and P2 for Reduction

Table 2. Cyclic Voltammograms Data of P1 and P2

\begin{tabular}{lccc}
\hline Polymers & Oxidation Potential (V) & Reduction Potential (V) & Eelectronic (eV) \\
\hline p(TT-Biphenyl) P1 & 1.28 & -0.75 & 2.03 \\
p(TT- Ant) P2 & 1.42 & -0.64 & 2.06 \\
\hline
\end{tabular}

\section{Conclusion}

In this work, two novel polymers, containing thienothiophene, anthracene and biphenyl groups, were designed and synthesized by Suzuki polymerization. Electronic and optical properties of the 
resultant polymers were investigated. UV, emission and CV values indicated that P1 and P2 are suitable materials for electronic and optical applications.

\section{References}

[1)] M. Emin Cinar and Turan Ozturk, Chem. Rev., 2015, 115, 3036 - 3140

[2] A. Capan, H. Veisi, A. C. Goren, T. Ozturk, Macromolecules, 2012.

[3] A. Capan, T. Ozturk, Synthetic Metals, 2013..

[4] L. Wang, C. S. Day, M. W. Wright, M. E. Welker, Beilstein J.Org. Chem. 2009, 5. Article 45c.

[5] A. Mishra, C.-Q. Ma, P. Ba€uerle, Chem. Rev. 2009, 109, 1141.

[6] W. Tang, L. Ke, L. Tan, T. Lin, T. Kietzke, Z. K. Chen, Macromolecules. 2007, 40, 6164.

[7] Kutahya, C.; Allushi, A.; Isci, R.; Kreutzer, J.; Ozturk, T.; Yilmaz, G.; Yagci, Y., Macromolecules, 2017, 50, 6903-6910.

[8] Yan Xie a,b, Liang Han a , Cheng-Sheng Ge b , Yan-Hong Cui a , Jian-Rong Gao a, Chem. Letters, 2017, 28(2)

[9] Yong Zhan, Kaiyu Cao, Pengchong Xue, Ran Lu; Tethrahedron Letters, 2013, 594-599 